\title{
PENDAMPINGAN PENDIRIAN KOPERASI JASA KEUANGAN SYARIAH SEBAGAI UPAYA MENANGGULANGI RENTENIR PADA MASYARAKAT DESA WURYANTORO LOR, KECAMATAN WURYANTORO, WONOGIRI
}

\author{
Mulyadi $^{1)}$ \\ Bambang Kusdiasmo ${ }^{2)}$ \\ P. Haryoso ${ }^{3)}$ \\ STIE “Adi Unggul Bhirawa” Surakarta \\ Email : mulyadi@stie-aub.ac.id
}

\begin{abstract}
ABSTRAK
Kemiskinan memberikan dampak negatif yang begitu banyak, kompleks dan sistemik, seperti sulitnya memperoleh pendidikan sehingga akan menyebabkan pengangguran, dengan adanya penggangguran tentu akan berdampak terhadap kriminalitas dan kekerasan, baik kekerasan di luar rumah maupun kekerasan dalam rumah tangga. Yang paling berbahaya adalah dampak terhadap aqidah umat Islam.Kondisi ini dimanfaatkan oleh orang-orang yang tidak bertanggungjawab seperti rentenir. Mereka memanfaatkan kemiskinan dengan memberikan pinjaman dengan mudah dan cepat tanpa agunan dengan konsekuensi bunga yang tinggi. Praktek rentenir yang menjerat hingga saat ini masih terjadi baik di desa maupun di kota. Meskipun kegiatan ini dengan tegas dilarang dalam agama Islam, dan juga tidak dibernarkan oleh pemerintah melalui undang-undang perbankan No. 10 tahun 2008 yang mengatur siapa saja yang boleh memberikan pinjaman kepada masyarakat, namun mereka masih tetap bergeriliya dimana-mana.Di Wuryantoro Lor Kecamatan Wuryantoro Kabupaten, keberadaan rentenir dianggap sudah meresahkan masyarakat, disatu sisi warga sudah terjerat akan dengan utang berbunga tinggi. Meskipun demikian keberadaan rentenir di daerah tersebut sudah berlangsung bertahuntahun, karena para rentenir memanfaatkan kemiskinan warga untuk menawarkan kemudahan pinjaman tanpa agunan dengan bunga tinggi. Dengan adanya workshop mengenai pendirian Koperasi Jasa Keuangan Sariah (KJKS) masyarakat sangat antosias untuk segera membentuk, karena sebelumnya Koperasi di masyarakat bisa dikalahkan oleh para rentenir. Maka tujuan didirikannya Koperasi Jasa Keuangan Sariah (KJKS) tidak hanya bersifat materialistis semata tetapi juga mempunyai tujuan yang sangat mendasar yaitu mengamalkan Al-Quran melalui ekonomi Islam dalam memberantas kemiskinan, memajukan ekonomi mikro, mendidik umat agar giat bekerja, jujur, memakmurkan masyarakat sekitar. Disamping itu dengan adanya Koperasi Jasa Keuangan Sariah (KJKS) diharapkan dapat menjalin kerjasama, saling menolong antara masyarakat yang kelebihan dana dengan yang kekurangan dana.
\end{abstract}

Kata Kunci: pengabdian kepada masyarakat, Rentenir, Koperasi Jasa Keuangan Syariah (KJKS)

\begin{abstract}
Poverty has so many complex, systemic negative impacts, such as the difficulty of getting an education that will lead to unemployment, with unemployment likely to have an impact on crime and violence, both outside violence and domestic violence. The most dangerous is the impact on the aqidah of Muslims. This condition is exploited by irresponsible people like loan sharks. They take advantage of poverty by providing loans easily and quickly without collateral with high interest consequences. The practice of loan sharks that ensnare to this day still occurs both in the village and in the city. Although this activity is strictly prohibited in Islam, it is also not authorized by the government through the banking law. 10 of 2008 which regulates who is allowed to lend to the community, but they still remain bergeriliya everywhere. In Wuryantoro Lor District Wuryantoro District, the existence of loan sharks is considered to be disturbing the community, on the one hand residents are already entangled will with high-interest debt. Nevertheless the existence of loan sharks in the area has been going on for years, as moneylenders take advantage of the poverty of citizens to offer the convenience of unsecured loans with high interest. With the workshop on the establishment of Syariah Financial Services Cooperative (SFSC) the community is very antosias to immediately form, because previously Cooperatives in the community can be defeated by the loan sharks. So the purpose of the establishment of Sariah Financial Services Cooperative (KJKS) is not only materialistic but also has a very basic purpose of implementing AlQuran through Islamic economics in eradicating poverty, promoting microeconomics, educating people to work hard, honest, prosperous society. Besides, with the existence of Financial Services Cooperative Syariah (SFSC) is expected to establish cooperation, mutual help between people with excess funds with the lack of funds.
\end{abstract}

Keywords: community service, Rentenir, Syariah Financial Services Cooperative (SFSC) 


\section{A. ANALISA SITUASI}

Krisis perekonomian yang sering menjadi alibi dalam memburuknya keadaan perekonomian nasional.Namum, tersebarnya usaha kecil di berbagai daerah dengan berbagai jenis usaha dalam bentuk barang dan jasa dapat menjadi sebuah peluang yang wajib diperhitungkan untuk memulihkan perekonomian saat ini yang sedang di ambang kehancuran.Hal ini dikarenakan usaha kecil bergerak di lapisan bawah ekonomi yang bergerak langsung di masyarakat.

Oleh karena itu sangat disarankan untuk mengembangkan KJKS di setiap daerah yang ada untuk membantu menuntaskan masalah perekonomian kelas kecil dan menengah di daerah dengan landasan syariah yang sangat dianjurkan oleh agaa Islam karena menghindari dan menolak keras riba.

Sekalipun KJKS menggunakan konsep syariah yang cenderung identik dengan umat islam, bukan berarti hanya masyarakat muslim saja yang bisa bergabung menjadi anggota dan menggunakan jasa KJKS. KJKS dan konsep syariah yang digunakan bisa dinikmati oleh umat manapun tak memandang agama dan suku karena pada dasarnya konsep syariah adalah konsep ekonomi yang universal yang berkeadilan.

Di Desa Wuryantoro Lor, Kec Wuryantoro Kabupaten Wonogiri merupakan daerah yang penduduknya rata-rata beragama islam. Disamping itu rata-rata penduduknya adalah petani.Mereka ketika ingin menggarap lahanya dibutuhkan modal yang cukup untuk membeli bibit dan pupuk.Modal yang dimiliki biasanya kurang, sehingga mereka mencari pinjaman di lembaga keuangan.

Akan tetapi Pemberi dana modal tersebut ratarata adalah para rentenir yang menganggap bahwa syarat pinjamannya mudah, bahkan tanpa menggunakan jaminan juga banyak, bahkan uang diberikan kerumah masyarakat yang meminjam, tetapi bunga yang dibebankan cukup tinggi, namun karena kemudahan tersebut masyarakat tetap mengambil dari para rentenir tersebut. Meskipun di desa itu juga ada koperasi tetapi karena perlakuannya sama dengan lembaga keuangan lain,maka tidak tetap banyak yang mengambil dari para rentenir.

Maka dari itu kami dari Tim Pengabdian Kepada Masyarakat STIE AUB Surakarta mencoba untuk menyadarkan kepada masyarakat agar mereka tidak terjebak pada rentenir yang membebani masyarakat dengan bunga yang tinggi.Yaitu membentuk Koperasi Jasa Keuangan Syariah yang sangat membantu masyarakat dalam membenahi perekonomian mereka lebih baik dan berkualitas.

\section{B. KERANGKA MASALAH}

PEMECAHAN

Tim Pengabdian kepada masyarakat STIE-AUB Surakarta setelah melakukan pengamatan di lapangan ternyata sebagian besar belum tahu tentang caramengelola koperasi dengan sistem syariah yang benar, sehingga diperlukan standar baku untuk memberikan pengetahuan bagi mereka tentan syariah terutama dalam pengelolaan keuangan yaitu PSAK 101.

Pemecahan masalah sbb :

1. Tentukan jumlah pengurus koperasidi Wuryantoro Lor Kec. Wuryantoro Kabupaten Wonogiri yang berminat mengikuti worshop wilayah kalurahan Nusukan

2. Tentukan tujuan menggunakan PSAK 101 dalam menyusun laporan keuangan

\section{TARGET LUARAN}

Target luaran diadakannya Program Pengabdian Masyarakat adalah :

Secara umum yang ingin dicapai dari kegiatan ini adalah agar para pengurus koperasidi Wuryantoro Lor Kec. Wuryantoro Kabupaten Wonogirimemiliki pengetahuan yang baik dalam mengelola koperasi berbasis syariah, sehingga dapat lepas dari para rentenir.

Dari luaran umum tersebut dapat dirinci lagi menjadi beberapa luaran khusus sebagai berikut : 1. Memberi pengetahuan terhadap anggota dan para pengurus koperasidi Wuryantoro Lor Kec. Wuryantoro Kabupaten Wonogiri, memiliki pengetahuan yang baik dalam melaksanakan kinerja berbasis syariah

2. Memberi pengetahuan terhadap para pengurus koperasidi Wuryantoro Lor Kec. Wuryantoro Kabupaten Wonogiri, memiliki pengetahuan yang baik dalam menyusun laporan keuangan berbasis syariah

3. Para pengurus pra koperasi dan anggota dapat memperbaiki systemmanajemen keuangan yang diharapkan tidak mengandung riba.

4. Menjauhkan dari para rentenir yang menjerat masyarakat karena bunga hutang tinggi.

\section{SOLUSI YANG DITAWARKAN}

Menyadari terhadappotensidanpermasalahanyang telahdiuraikan diatas, makadiperlukan adanyakegiatanataupelatihanyang

mampuuntukmemecahkan permasalahanyang berkaitandiatas,solusipermasalahan tersebutdapatdiuraikan sebagaiberikut:

1. Menjelaskan keberadaan Koperasi Syariah dapat membantu masyarakat dalam menjauhkan dari para rentenir.

2. Menjelaskan tatacara mendirikan koperasi syariah 
3. Memberikan pelatihanmanajemen syariah kepada pengurus koperasi dan anggota koperasi.

\section{E. KHALAYAK SASARAN}

1. Para pengurus koperasidi Wuryantoro Lor Kec. Wuryantoro Kabupaten Wonogiri.

2. Para anggota koperasidi Wuryantoro Lor Kec. Wuryantoro Kabupaten Wonogiri

\section{F. METODE PELAKSANAAN}

Kegiatan ini akan dilakukan dengan metode :

1. Ceramah : dengan memberikan penjelasan secara langsung dari pada materi dengan menggunakan makalah kepada masyarakat anggota dan pengurus koperasi di Wuryantoro Lor Kec. Wuryantoro Kabupaten Wonogiri.

2. Pelatihan : Yaitu memberikan pemahaman kepada pengurus koperasi untuk dapat mengelola pra koperasi dengan berbasis syariah

3. Sarasehan : Yaitu memberikan ceramah, penyuluhan dan pelatihan beberapa hari untuk sampai mendapatkan pemahaman yang baik bagi pengurus dan anggota koperasi di Wuryantoro Lor Kec. Wuryantoro Kabupaten Wonogiri.

4. Pendampingan : Yaitu melakukan pendampingan pada saat ada kesulitan dalam proses pengelolaan koperasi Syariah.

\section{G. PEMBAHASAN}

Sesuai dengan rencana yang telah ditentukan sebelum kegiatan pelatihan dilaksanakan, kegiatan ini diawali dengan penyiapan berbagai adiministrasi diperlukan antara lain permohonan ijin melaksanakan pengabdian masyarakat, undangan peserta pelatihan, undangan kepada kepala dinas koperasi di Kabupaten Wonogiri. Koordinasi dengan Dinas Koperasi untuk waktu dan tempat pelatihan, penyiapan materi pelatihan tentang penyusunan laporan keuangan serta penyiapan Jadwal pelatihan. Berikut ini akan diuraikan hasil yang dicapai terkait dengan pelatihan tata cara pendirian koperasi Jasa Keuangan Syariah

1. Peserta Pelatihan

Peserta yang hadir dalam pelatihan ini adalah sejumlah 30 orang peserta terdiri dari para anggota danpengurus koperasi di Wuryantoro Lor Kec. Wuryantoro Kabupaten Wonogiri.Kegiatan ini diawali dengan sambutan ketua Dinas Koperasi Surakarta yang diwakili oleh Bapak Sukarno, dilanjutkan dengan penyampaian tata cara pendirian koperasi syariah 2. Penyiapan Materi

Materi yang disiapkan pada pelatihan ini meliputi Pengertian koperasi simpan pinjam Syariah, Perbedaan BMT dengan Koperasi Simpan Pinjam Syariah, Manajemen Koperasi
Simpan Pinjam Syariah KJKS dan Jenis Simpanan Koperasi Simpan Pinjam Syariah. Materi tersebut disiapkan dalam bentuk Powerpoint, dan dalam bentuksoal-soal kasus pada koperasi syariah

3. Kegiatan Pelatihan

Kegiatan pelatihan ini dilaksanakan tgl 20 Januari 2018 bertempat di Wuryantoro Lor Kec. Wuryantoro Kabupaten Wonogiri.. Kegiatan pelatihan ini terdiri dari tiga tahapan yang meliputi pemberian materi, diskusi, dan praktik caramendirikan Koperasi Jasa Keuangan Syariah a. Pemberian Materi

Pemberian materi pelatihan ini berlangsung selama 2 jam. Materi yang disampaikan antara lain pengertian syariah, Tata cara pendirian Koperasi Syariah danManajemen koperasi Jasa Keuangan Syariah

b. Diskusi

Setelah penyampain materi diakhiri kemudian dilanjutkan dengan diskusi, diskusi ini berlangsung dengan tertib dan terarah. Pada saat diskusi peserta berperan aktif bertanyaterkait dengan permasalahan yang mereka hadapi di usaha mereka masing-masing

\section{c. Pendampingan}

Pendampingan dilakukan dalam kurun waktu 6 bulan setelah menerapkan sistem syariah dilakukan monitoring terhadap kinerja pengurus apakah sudah sesuai dengan PSAK 101 yaitu mengelola koperasi berbasis syariah

\section{H. PENUTUP}

\section{SIMPULAN}

Dari hasil pelatihan dari peserta pengurus koperasi di Wuryantoro Lor Kec. Wuryantoro Kabupaten Wonogirisudah mampumemahami KJKS Merupakan Koperasi simpan pinjam yang menjalan kan kegiatan usahanya berdasarkan prinsip bagi hasil atau syariah, disamping itu prinsip pendirian Koperasi berbasis syariah memberikan pencerahan bagi masyarakat didalam menjauhkan dari para rentenir karena menjerat dengan hutang atas bunga yang tinggi, yang akan berdampak justru pada kemiskinan. Maka KJKS dapat menyadarkan masyarakat bukan hanya dari sisi material tetapi yang lebih mendasar adalahmengamalkan Al-Quran melalui ekonomi Islam dalam memberantas kemiskinan, memajukan ekonomi mikro, mendidik umat agar giat bekerja, jujur, memakmurkan masyarakat sekitar

\section{SARAN}

Berdasarkan hasil kegiatan dapat disarankan hendakanya tidak hanya pad pengurus dan anggota koperasi saja yang tahu tentang pengetahuan Koperasi Jasa Simpanan Syariah, 
tetapi juga masyarakat yang mengerti akan keberadaan koperasi Jasa Simpanan Syariah akan bermanfaat baik di dunia dan di akhirat.

\section{DAFTAR PUSTAKA}

Ikatan Akuntan Indonesia. (2009). Standar Akuntansi Keuangan Syariah Dewan Standar Akuntansi Keuangan Jakarta

Peraturan Menteri Negara Koperasi dan Usaha Kecil dan Menengah RI Nomor 91/Kep/M.Kukm/IX/2004 Tahun 2012. Tentang Koperasi tentang Petunjuk Pelaksanaan Koperasi Jasa Keuangan Syariah

Peraturan Menteri Negara Koperasi dan Usaha Kecil dan Menengah RI Nomor 35.3/Per/M.Kukm/X/2007 tentang Petunjuk Kesehatan Koperasi Jasa Keuangan Syariah

Ridwan, Ahmad Hasan,2014;'’Instrumen Lembaga Keuangan Syariah”, Bandung, Pustaka Bany Quraisy

Undang-undang No.17Th 2015 